\title{
Bioética e Dignidade da Pessoa Humana: Rumo à Construção do Biodireito
}

\author{
Gudith ollaxtins- Costa \\ Doutora em Direito pela Universidade de São Paulo, Professora Adjunta na \\ Faculdade de Direito da Universidade Federal do RS e Membro do \\ Comitê de Bioética do Hospital de Clínicas de Porto Alegre.
}

"Combien durera ce manque de l'homme mourant au centre de la création parce qu la création l'a congedié?" (René Char, A La Santé du Serpent, VIII, Commune Presence)

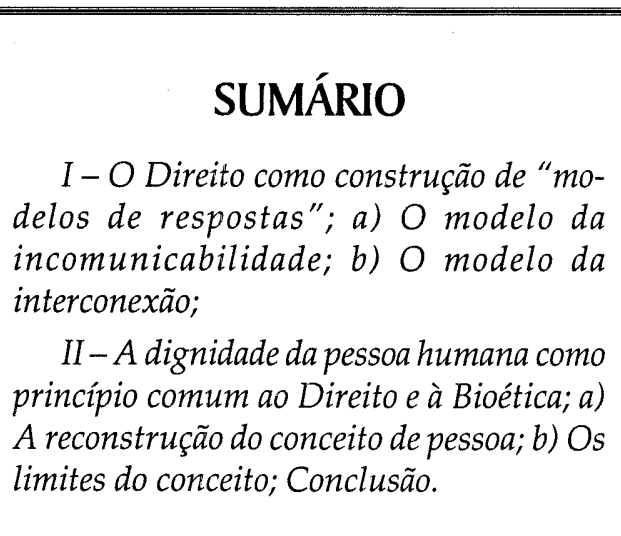

\section{SUMÁRIO}

$I-O$ Direito como construção de "modelos de respostas". a) O modelo da incomunicabilidade; b) O modelo da interconexão; A reconstruç̃o do conceito de pessoa; b) Os limites do conceito; Conclusão.
( anúncio pela comunidade científi ca internacional, do "mais importante mapa feito pela humanidade", como disse o Presidente Clinton ao aludir ao seqüenciamento do código genético, faz sair a reflexão bioética das salas das universidades para situá-la como um tema de interesse do homem comum, do leitor dos grandes jornais - este mesmo leitor que, em 1997, restou perplexo, quando noticiados os resultados das experiências realizadas pelo Doutor IAN WILLMULT que resultaram na criação da célebre ovelha Dolly.

A estupefação do leitor de jornais reflete, em larga medida, a perplexidade do

1. Este texto é, com adições, 0 apresentado em 2.07 .2000 ao III Congresso Brasileiro de Bioética e I Congresso de Bioética do Conesul, PUCRS, Porto Alegre no painel "Interrelaçōes entre a Bioética e o Direito", constituindo estudo preliminar acerca do tema, tal como vem sendo desenvolvido em Grupo de Estudos coordenado pela autora no âmbito da Facul. dade de Direito (Graduação e Pós-Graduação) da UFRGS como líder do Grupo de Pesquisa "A construcão do biodireito: a normatividade juríica da bioética", do CNPq. 
jurista: ela não é devida, contudo, como a do leigo, apenas aos inacreditáveis fatos científicos, mas é acrescida por uma dúvida crucial: como compatibilizar a reflexão ética propiciada pelos novos paradigmas científicos com a racionalidade "utilitarista" comumente atribuída ao regramento jurídico? A razão prática está na preocupação do jurista na medida em que o Direito não apenas "é" a produção de normas, ele também "serve" à produção de normas destinadas a resolver casos mediante decisões, para alcançar escolhas e ações de relevância social, ${ }^{2}$ no seu fulcro residindo, portanto, uma aporia fundamental - saber o que é justo, aqui e agora, pois a cada problema social concreto uma resposta, também concreta e imediata, deve ser dada pelos Tribunais.

À questão de saber como compatibilizar a reflexão ética propiciada pelos novos paradigmas científicos com a racionalidade prática do regramento jurídico - que traduz, afinal, a complexidade das interfaces entre a Bioética e o Direito subjazem outros problemas igualmente complexos. Respondê-la implica questionar: Para que serve o Direito? Como ele é feito? Como ele é aplicado? Implica desmentir certas concepções que vêem o Direito como o produto de um legislador demiúrgico e autoritário; implica fundamentalmente falar do Direito como "regulamentação coordenada dos comportamentos sociais", regulamentação, contudo, que não se desvincula da experiência social concreta, e que constitui a síntese de uma tríade segundo a concepção de MIGUEL REALE - entre fato, valor e norma, isto é, o fato social, o valor ético que lhe é atribuído por cada sociedade, em cada momento da sua história, e, finalmente, a escolha deste fato, valorado eticamente, por uma norma dotada de poder de coerção, como o é a norma jurídica. ${ }^{3}$

Responder àquela questão implica, por igual, situar o escopo da Bioética e o não consensual entre os estudiosos e aventar a possibilidade da construção de um Biodireito, tema ainda menos consensual na doutrina.

$\mathrm{Na}$ arriscada tentativa de alinhavar algumas respostas a estas questões, proponho o exame do tema a partir da compreensão dos modelos de construção das respostas jurídicas (I). Posteriormente, examino se há princípios comuns que possam atuar como ponte entre a reflexão bioética e a construção de soluções jurídicas (II).

\section{I - O Direito como construção de modelos de respostas}

Foi o racionalismo iluminista que pensou o fenômeno jurídico como um sistema de regras, dividindo a experiência social em dois distintos planetas - o planeta do Direito e o planeta do não-Direito. Foi a assunção pelo Estado, na Revolução Franseu estatuto epistemológico, matéria ainda

2. F. VIOLA e G. ZACCARIA. Diritto e Interpretazione - Lineamenti di teoria ermeneutica del diritto. Roma: Laterza, 1999, p. 402.

3. Sobre o tridimensionalismo veja-se em especial, Teoria Tridimensional do Direito, 5. ed. Saraiva, 1994, Verdade e Conjetura, Ed. Nova Fronteira, 1983, Fundamentos do Direito, 3. ed. Revista dos Tribunais, 1998, e Fontes e Modelos do Direito - para um novo Nova Fronteira, 1983, Fundamentos do Dir
paradigma hermenêutico, Saraiva, 1994.

Revista da Faculdade de Direito da UFRGS, v. 18, 2000 cesa, da tarefa de criar as regras jurídicas e arrumá-las em conjuntos de leis - os códigos - que fez o ordenamento jurídico aparecer como um sistema fechado de regras, postas por ato de autoridade estatal, regras que traduziriam a totalidade dos comportamentos sociais merecedores de tutela jurídica, sendo, por isto, excludentes de outras fontes de normatividade. E foi, enfim, o cientificismo oitocentista-prolongado, em larga escala, no século XX - que tentou perspectivar o Direito numa ciência "pura", isto é, livre da "contaminação" de outros setores vitais da experiência humana, como a Ética, a História, a Economia. ${ }^{4}$

A concepção derivada dessas idéias vigorantes nos últimos 200 anos, foi conhecida como legalismo, termo que indica a pretensão de reduzir o fenômeno jurídico a uma de suas manifestações - a lei de origem parlamentar - fazendo crer à sociedade que, a cada novo problema, seria necessária a intervenção autoritária do legislador para fazer com que a nova realidade, saindo do obscuro campo do "não-Direito" fosse, assim, jurisdicizada.

Esta concepção foi, contudo, posta em crise no século XX, principalmente na sua segunda metade. ${ }^{5}$ Diferentemente do que ocorria no passado, hoje o Direito não é visto tão só como ciência, mas, fundamentalmente, como prudência, como arte prudencial que está interrelacionada, fun- damentalmente, com as demais instâncias componentes do todo social, notadamente a Ética. A sociologia aponta ao fenômeno das leis que "não pegam", isto é, que não têm verdadeira eficácia social, porque divorciadas da realidade do seu tempo, dos suportes éticos que as tornariam consensualmente aceitáveis.

Por isto, o acerto da concepção pela qual as normas jurídicas que resultam das fontes constituem, por certo, expressão de modelos prescritivos, sendo porém dotados de um essencial sentido prospectivo, ${ }^{6}$ consistindo a positivação das normas um verdadeiro processo de positivação. Superado o dogma da estaticidade da produção normativa - como se o positivar de regra jurídica consistisse num único e isolado ato, o de "pôr" o Estado a regra, por um ato de autoridade chamado "promulgação" - foi possível perceber o caráter dinâmico da positivação, a qual é como composta por dois complexos momentos: um, estático, fixo e atomístico, qual seja, a promulgação, por ato de autoridade, em regra, a autoridade legislativa; e outro dinâmico, processual e "total".

Diz-se que este segundo momento é dinâmico e processual porquanto é progressivamente estabelecido pelos destinatários do ato político estatal, a comunidade, sejam os que têm por função interpretar e aplicar as regras legais (juízes e funcioná-

4. Sobre o tema o meu A Boa-Fé no Direito Privado, Ed. Revista dos Tribunais, 1999, em especial Parte I.

5. Para este exame, veja-se, entre tantos, K. LARENZ, Metodologia da Ciência do Direito, trad. de José Lamego, 3. ed. Fundaçăo Calouste Gulbenkian, 1997, Parte Histórico-Crítica.

6. REALE, Miguel. Fontes e Modelos, cit., p. 30.

Revista da Faculdade de Direito da UFRGS, v. 18, 2000 
rios administrativos), ${ }^{7}$ sejam os cidadãos, membros da comunidade juridicamente organizada. Por esta razão, compreende-se que o "dever-ser" ínsito à norma jurídica não é um mero enunciado lógico mas, como afirmou MIGUEL REALE, "um dever-ser que se concretiza na experiência social correlacionando-se com conjunturas factuais e exigências axiológicas". 8

Da alteração da concepção de fonte chegou-se, por igual, à alteração do mode lo pelo qual se expressa a normatividade mesmo na fonte legal: ao lado dos modelos cerrados, nos quais o fato da vida, ou comportamento social devido, vem perfeitamente caracterizado e conectado a uma determinada conseqüência - isto é, o chamado modelo da tipicidade, na qual há uma espécie de pré-figuração, pelo legislador, do comportamento típico - passa-se a utilizar em certas disciplinas, como o Direito Civil e o Constitucional, também modelos aber tos. Nestes o legislador não desenha o comportamento típico, ao contrário, utiliza uma linguagem intencionalmente vaga, aberta fluída, caracterizada pela ampla extensão do seu campo semântico. ${ }^{9}$

Estes modelos abertos, vazados em linguagem "vaga", são apropriados para canalizar, juridicamente, as exigências axiológicas fundamentais da comunidade, tanto na Bioética quanto no Direito. Por isto, afirma-se que estas vêm expressas preferencialmente em princípios. Compreendem hoje os juristas que o ordenamento é composto por princípios e por regras, ambos espécies integrantes de um mesmo gênero, o das normas jurídicas. ${ }^{10}$

O ordenamento jurídico apresentase, assim, não como um sistema fechado de regras que têm a pretensão da plenitude legislativa e da completude lógica, mas como um sistema aberto de princípios e regras, constituindo a sua positivação um processo no qual intervém o legislador, o juiz e a comunidade.

O que são princípios jurídicos? Inúmeras respostas têm sido dadas a esta questão, e entre elas a resposta de ALEXY, segundo o qual princípios são o mesmo que valores. Porém, como o Direito trata do que deve ser, do que é devido, há entre ambos

7. Ver G. ZACCARIA. Sul Concetto di Positività del Diritto", in "Diritto Positivo e Positività del Diritto, org. G. Zaccaria, Ed. Giappichelli, Milăo, 1989, p. 329, e ainda: "La positività giuridica non costituisce e non può essere concepita come l'espressione pressochè esclusiva di un autorità che pone, quanto piuttosto come l'esito di un procedimento e di una prassi articolata di soggetti, che continuamente si fanno".

8. REALE, Miguel. Op. cit., p. 31.

9. Ao invés de descrever a factualidade, emprestando-the determinada conseqüência jurídica, o legislador reconhece que é impotente para apreender, previamente, a totalidade das situaçōes de vida merecedoras de tutela jurídica. Por isto, em determinadas situações, notadamente aquelas em que os padrões sociais não estão firmemente assentados, ou não podem ser assentados sena̧o de forma provisória, como ocorre com os padrões técnicos e científicos, limita-se o legislador a conferir, mediante o modelo aberto, uma espécie de "mandado" para que o juiz possa, progressivamente, e à vista da alteraçăo nos paradigmas sociais,

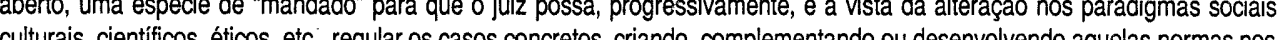
collurais, " indicaçoes de fins a perseguir ou de valores a garantir (Acerca da linguagem das cláusulas gerais escrevi em A Boa-Fé no Direito Privado, cit. Pp. 273 a 380 ).

10. ALEXY, Robert. Teoria de los Derechos Fundamentales, trad. esp. de Ernesto Garzón Valdés, Ed. Centro de Estudios Constitucionales, 1993, p. 81 e ss.

Revista da Faculdade de Direito da UFRGS, v. 18, 2000 os conceitos uma diferença a ser notada. Utilizando a classificação de VON WRIGHT ${ }^{11}$ entre conceitos deontológicos (v.g., mandato, dever-ser, ordem, proibição, permissão, direito a), axiológicos (v.g., bom mau, belo, corajoso, seguro) e antropológi$\cos$ (v.g., vontade, interesse, necessidade decisão). ALEXY assenta a distinção: "Princípios e valores são o mesmo, contemplado em um caso sob um aspecto deontológico e sob um aspecto axiológico". ${ }^{12}$

Como nos princípios é ainda mais nítida a processualidade e dinamicidade da positivação - pois deve haver uma espécie de adesão moral da comunidade que permita a sua concreção mediante determinados significado e alcance - observa-se a razão pela qual, por intermédio dos princí pios o Direito reaproxima-se da dimensão ética, afastada que fora pelo formalismo legalista, apresentando-se como um sistema axiologicamente orientado. ${ }^{13}$ Ao modelo da incomunicabilidade entre o Direito e as demais instâncias do todo social notadamente a Ética, substitui-se o modelo da conexão, comunicabilidade e complementaridade.

Ilustrativa deste novo modelo é a Constituição Federal. Diferentemente do que ocorria no passado, quando às Constituições era emprestada a missão de tão-so-

mente definir as normas de organização e competência do Estado, hoje em dia temse a "Constituição principiológica", que transforma em direito positivo, direito legal, certos princípios que tradicionalmente eram tidos como pré-positivos, como, por exemplo, o princípio da dignidade da pessoa humana, entre nós expressamente reconhecido como princípio estruturante ou fundante do Estado Democrático de Direito. ${ }^{14}$

Inscritos comumente em cláusulas gerais, caracterizando o que se convencionou chamar de "conceitos jurídicos indeterminados", os princípios ensejam uma nova maneira de aplicar o Direito: ao juiz hoje é reconhecida a competência de não apenas subsumir certos fatos às regras que os descrevem, mas, igualmente, o poder de concretizar - isto é - tornar concretos, atuantes e operativos os princípios que traduzem valores.

Estas transformações metodológicas possibilitam a crítica e a reconstrução de certos conceitos fundamentais do Direito, abrindo espaço, por igual, à construção do Biodireito, termo que indica a disciplina, ainda nascente, que visa determinar os limites de licitude do progresso científico, notadamente da biomedicina, ${ }^{15}$ não do ponto de vista das "exigências máximas" da

11. In The Logic of Preference, apud Alexy, op. cit., pp. 139 e 140.

12. ALEXY, Robert. Teoria de los Derechos Fundamentales, op. cit., p. 147.

13. CANARIS, Claus-Wilhem Canaris. Pensamento Sistemático e Conceito de Sistema na Ciência do Direito, trad. Menezes Cordeiro, Ed. Fundação Gulbenkian, 1989, p. 66 e ss.

14. $C F$, art. 19, inc. III.

15. PALAZANNI, Laura. II concetto di persona tra bioetica e diritto. Turim: Giappichelli, 1996, p. 9. 
fundação e da aplicação dos valores morais na praxis biomédica - isto é, a busca do que se "deve" fazer para atuar o "bem" - mas do ponto de vista da exigência ética "mínima" de estabelecer normas para a convivência social. ${ }^{16}$ Assim é que, muito embora recebendo contestações - porque importaria na "jurisdiciarização" indevida da biomedicina - mesmo assim tem crescido o endosso à formação do Biodireito como disciplina jurídica da bioética. ${ }^{17}$

O Direito desenvolve-se na História, e, por isto, um de seus papéis é o de mediar a dialética que por vezes resta estabelecida entre a tradição e a ruptura, entre os processos de continuidade e os de descontinuidade social. Seu papel não é, pois, o de cercear o desenvolvimento científico mas, justamente o de traçar aquelas exigências mínimas que assegurem a compatibilização entre os avanços biomédicos que importam na ruptura de certos paradigmas e a continuidade do reconhecimento da Humanidade enquanto tal, e, como tal, portadora de um quadro de valores que devem ser assegurados e respeitados.

Para o estabelecimento destas "exigências mínimas" interessará basicamente o conceito de pessoa humana, hoje em plena reelaboração teórica.

16. Idem, pp. 9 e 10

17. Anota PATRICK FRAISSEIX: "la question de la nécessité comme de l'opportunité d'une judiciarisation' de la biomédecine mérite dềtre aujourd"hui dépassée gace aux prodiges parfois inquietants réalisés par la science" (La protection de la dignité de la personne et de l'espèce humaines dans le domaine de la biomédecine: l'exemple de la Convention d'Oviedo, Revue Internationale de Droit Comparé, 2, avril-juin 2000, p. 374). 18. A expressão é de A J. GREIMAS, em Semiótica e Ciências Sociais, tradução de Alvaro Lorencini e Sandra Nitrini. São Paulo:
Cultrix, 1981, p. 75 ss.

Revista da Faculdade de Direito da UFRGS, v. 18, 2000

\section{II - A Dignidade da pessoa humana como princípio comum ao Direito e à Bioética}

Sob o seu estatuto epistemológico particular, o Direito também se ocupa da vida - do nascer e do morrer, de quem é pessoa, de sua filiação, de seus valores existenciais e de suas relações patrimoniais, de seus direitos (isto é, dos direitos que concernem à pessoa) e de seus deveres e responsabilidades. Portanto, falar em Direito é falar fundamentalmente em pessoa e em relação - o modo como se estabelecem as relações entre as pessoas (individual ou coletivamente consideradas), e as relações das pessoas com as coisas, bens materiais e imateriais.

Se em nosso horizonte axiológico o mais relevante for a relação entre a pessoa e os bens, economicamente avaliáveis, cresce em importância a idéia de pessoa como sujeito titular de um patrimônio. Essa idéia foi a modulada pela Era Codificatória, assim entendida a que se seguiu às grandes codificações oitocentistas correspondentes à ascensão do individualismo burguês e do capitalismo. Aí foi desenhada a idéia de pessoa como "sujeito" e como "indivíduo".

O discurso jurídico é sempre um discurso conotado ${ }^{18}$ e, por recorrências lexicais diversas, seu dicionário é de certa forma, autônomo. ${ }^{19}$ Pessoa, Sujeito, Personalidade são palavras que têm diversas conotações no tempo e no espaço. ${ }^{20}$ No discurso pandectista do século XIX, a palavra "sujeito" depreendeu-se das subjetividades que mais tarde a psicanálise viria revelar e conotou-se a uma idéia externa, objetivada, por assim dizer, a idéia de um "sujeito" que é visto tão-só como "termo" ou "elemento" da relação jurídica, como aquele que pode (é capaz de) ser titular de direitos, atuando na ordem jurídica. Sujeito que é privilegiadamente o "indivíduo", porque não mais definido pela pertença a um grupo, casta, classe, família, status, porque apartado (dividido) de um todo, de uma comunidade que o ultrapassa: ${ }^{21}$ significações reveladoras da "lógica proprietária"22 que revestiu a própria idéia de pessoa humana.
Submergida a idéia de "pessoa" na de "indivíduo" (ao senso "egoísta" do termo) e não visualizada a de "personalidade" pela preeminência do conceito técnico de "capacidade", traçaram-se as tramas semânticas que acabaram por fundir o "ser pessoa" com o "ser capaz de adquirir direitos e contrair obrigações". Em outras palavras, instrumentalizou-se a personalidade humana, reproduziu-se, na sua conceituação, a lógica do mercado, o que conduziu à des. valorização existencial da idéia jurídica de pessoa, para torná-la mero instrumento da técnica do Direito, ${ }^{23}$ ponto que foi percebido com especial nitidez pela civilista argentina AIDA KEMELMAJER DE CARLUCCI segundo a qual, sob a ótica codificatória oitocentista o dano (el mal hecho) à pessoa se justificava "en la supuesta existencia de un verdadero derecho del sujeto

19. A J. GREIMAS. Semiótica e Ciências Sociais, cit., 76.

20. Como sintetiza com precisão MAREN TABORDA, com base na lição de RICCARDO ORESTANO (In "Il) Problema delle persone giuridiche" in Diritto Romano. Turim: Giappichelli, 1968), "no Direito Romano antigo, a palavra 'pessoa' tinha o significado normal de 'homem', sem qualquer alusão à sua capacidade. Embora largamente empregado, o termo persona não tinha um valor técnico, e tanto era 'pessoa' o homem livre quanto o escravo - persona servi -, ainda que este não fosse considerado sujeito de direito. Para o ser sujeito de direito, além da condição 'ser homem', concorriam mais três, a saber: ser livre, cidadão e senhor de si mesmo - sui iuris. Só nos textos pós-clássicos é que emerge um emprego diverso do termo, para exprimir uma noção que se avizinha ao que os modernos entendem por "capacidade jurídica". A mesma indistinção entre " "ser humano" 00 "ser pessoa" continuou na compilação justinianéia e - recorro ainda a Maren Taborda - "os glosadores civilistas bolonheses continuaram a não lhe atribuir, em referência ao homem, qualquer particular significação jurídica, sendo apenas na canonística, mais precisanão lhe atribuir, em referéncia a homem, qualquer particular significaçáa juridica, sendo apenas na canonistica, mais precisara designar entidades coletivas com uma configuração unitária e abstrata distinta de seus membros particulares". (A Publicização designar entidades coletivas com uma configuração unitária e abstrata distinta de seus membros paticu
da noção de pessoa juríica como fator de construção da dogmática do "Estado de Direito", inéito).

21. Da literatura, mais do que dos tratados jurídicos, vem esta compreensão. Lembro, a propósito, de "Au plaisir de Dieu", o romance de Jean D'Ormesson (Paris: Gallimard, 1974).

22. Aexpressão é de DAVIDE MESSINETTI, Personalitá (Diritti della), verbete. In Enciclopedia Giuridica. Milão: Giuffrè, 1984, p. 356

23. Veja-se as observaçōes de HANS HATTENHAUER, Conceptos Fundamentales del Derecho Civil, tradução espanhola de PABLO SALVADOR CODERCH, demonstrando as razōes pelas quais desde Kant ter assentado na Metafisica dos Costumes que "pessoa é o sujeito cujos atos podem ser a si próprio imputados" operou-se a transmutaçăo da idéia de "pessoa" para a de "sujeito", abrindo caminho para a consideração da pessoa como "mero material para a construçãa de relaçôes jurídicas", reduzindo-se a idéia de personalidade à noção de "capacidade de direito". Na doutrina brasileira veja-se ALEXANDRE DOS SANTOS CUNHA, "Dignidade da Pessoa Humana: conceito fundamental do Direito Civil", ensaio integrante de A reconstruçãa do Direito Privado reflexos dos princípios constitucionais e dos direitos fundamentais no Direito Privado, org. Judith Martins-Costa, no prelo.

Revista da Faculdade de Direito da UFRGS, v. 18, 2000 
sobre el próprio cuerpo, concebido a imagen y semejanza del derecho de Propiedad". ${ }^{24}$ A fra se "eu sou dono de meu corpo" expressa lapidarmente esta lógica. $O$ corpo humano, reificado, é visto como objeto de um direito de propriedade, integrante de um patrimônio individual, e, como os demais bens patrimoniais, pode ser objeto de mercancia. ${ }^{25}$

Mas, se, ao invés da relação entre a pessoa e os bens em primeiro plano estive a pessoa humana valorada por si só, pelo exclusivo fato de ser "humana" - isto é, a pessoa em sua irredutível subjetividade e dignidade, dotada de personalidade singular - passa o Direito a construir princípios e regras que visam tutelar essa dimensão exis tencial, ${ }^{26}$ não-patrimonial, mas ligada fun damentalmente à proteção da pessoa e da personalidade humana e daquilo que é o seu atributo específico, a qualidade de "ser humano".

A valorização desta dimensão tem origem, paradoxalmente, na barbárie do século XX - o totalitarismo estatal, ${ }^{27}$ eco- nômico ou científico ${ }^{28}$ - o qual teve como contrapartida a afirmação do valor da pessoa como titular da sua própria esfera de personalidade que, antes de ser vista como mero suposto do conceito técnico de capacidade, fundamenta-se no reconhecimento da dignidade própria à pessoa humana. Esta é a "novidade" que tem, para o Direito, o princípio da dignidade da pessoa. Como explica BERNARD EDELMAN, ${ }^{29}$ embora a palavra "dignidade" fosse há muito conhecida, e a idéia de uma dignidade própria ao homem remonte à filosofia de Kant, a idéia da existência de uma proteção jurídica que é devida em razão da dignidade liga-se fundamentalmente a um duplo fenômeno, a barbárie nazista (que fez alcançar a idéia de crimes contra a humanidade, no Tribunal de Nuremberg) e à biomedicina, que coloca em xeque a própria identidade da humanidade como espécie.

Por este caminho, não isento de paradoxos e de décalages, opera-se um câmbio semântico específico, verifica-se a
24. Codigo Civil y leyes complementarias. Comentado, anotado y concordado, dirigido por BELLUSCIO y ZANNONI. Buenos Aires: Astra, 1984, p. 34, comentário ao art. 68, apud J: Moisset Iturraspe, El daño fundado en la dimension del hombre, Revista de Derecho Privado y Comunitario, 1,1995 , p. 34.

25. Veja-se o instigante texto de MARIE-ANGĖLE HERMITE, "Le corps hors du commerce, hors du marché", Archives de Philosophie du Droit, T. 33, p. 323 e ss., na qual propōe a categorização das "coisas de origem humana" como escapatória à lógica do mercado para a apreciação, daquilo que, no corpo, pode ser objeto de relação jurídica (sangue, órgãos, etc.).

26. Por esta razão, e, aliás, como tudo no Direito, o conceito de pessoa não é "dado", mas um "construído Expressou com rara felicidade esta idéia François Miterrand, em mensagem dirigida em 1985 aos participantes de colóquio sobre genética, procriação e direito, ao afirmar: "a história dos direitos do homem é a história da própria noção de pessoa humana, da sua dignidade, da sua inviolabilidade". ("Atas do Colóquio Genétique, Procréation et Droit", Actes Sud, PUF, 1985, p. 14, cit., por Mário Raposo, Procriação Assistida - Aspectos Éticos e Jurídicos, p. 91).

27. Acerca dos vários totalitarismos, notadamente o político, veja-se CELSO LAFER, A Reconstrução dos Direitos Humanos - um diálogo com o pensamento de Hannah Arendt. São Paulo: Companhia das Letras, 1991.

28. Acerca especialmente do totalitarismo da ciência veja-se BERNARD EDELMAN, "Sujet de droit et technoscience", in La personne en danger. Paris: PUF, 1999, p. 397.

29. "La dignité de la personne humaine, un concept nouveau", in La personne en danger. PUF, 1999, p. 505.

Revista da Faculdade de Direito da UFRGS, v. 18, 2000 passagem de um grau de significação a outro: a dignidade da pessoa, como princípio jurídico, vai designar não apenas o "ser da pessoa", mas a "humanidade da pessoa". ${ }^{30}$ Esta é vista de uma perspectiva que não a confunde conceitualmente com o "sujeito capaz juridicamente", nem com o indivíduo atomisticamente considerado, significando diversamente, "a reunião simbólica de to dos os homens naquilo que eles têm em comum, a saber, a sua qualidade de sere humanos. Em outras palavras, é ela que permite o reconhecimento de uma perten ça (appartenance) a um mesmo 'gênero': gênero humano". ${ }^{31}$ A mudança de grau no significado está em que a dignidade é o atri buto ou qualidade desta pertença: "se to dos os seres humanos compõem humanidade é porque todos eles têm esta mesma qualidade de dignidade no 'plano' da humanidade; dizemos que eles são to dos humanos e dignos de o ser". 32

Por isto é que, mais do que uma "vazia expressão", como poderiam pensar os que estão ainda aferrados à concepção legalista estrita do ordenamento jurídico, a afirmação do princípio, que nos mais dife rentes países tem sido visto como um princípio estruturante da ordem constitucional ${ }^{33}$

- apontando-se-lhe inclusive um valor "refundante" da inteira disciplina privada ${ }^{34}$ - significa que a personalidade humana não é redutível, nem mesmo por ficção jurídi$\mathrm{ca}$, apenas à sua esfera patrimonial, possuindo dimensão existencial valorada juridicamente na medida em que a pessoa, considerada em si e em (por) sua humanidade, constitui o "valor-fonte" que anima e justifica a própria existência de um ordenamento jurídico.

É o que assinala o civilista argentino ORGE MOSSET ITURRASPE em termos candentes ao aludir à construção da categoria dos danos à pessoa: "Afirmamos desde ya que se trata de un cambio revolucionario. De una modificación que dice del humanismo del enfoque actual y de la deshumanización del Derecho ante. rior". ${ }^{35}$ É, por igual, a perspectiva adotada pelo peruano CARLOS FERNANDEZ SESSAREGO, pioneiro na América Latina no destacar a proteção jurídica à pessoa humana: "Referirse a la protección de la persona humana supone, como cuestión previa, determinar que tipo de ente es ella, considerada en si misma, per se. Es decir indagar por la naturaleza misma del ser sometido a protección jurídica", pois é "la

30. Idem, p. 507

31. Idem, p. 509, traduzi.

32. Idem, ibidem, traduzi.

33. Acolhem a dignidade da pessoa humana como princíio constitucional, entre outros países, a ltália (art. $3^{\circ}$ da Constituição de 1947), a Alemanha (art. 1², alínea I da Lei Fundamental de Bonn), a Grécia (art. $7^{\circ}$ da Constituiçăo de 1975), Portugal 9 arts. $1^{\circ}$ $13, \S^{2} \mathrm{e} 26, \S 2^{\circ}$ da Constituição de 1976), a Espanha (art. 10, $\$ 1^{2}$ da Constituição de 1978).

34. Na literatura italiana, PIETRO PERLINGIERE, II Diritto Civile nella Legalità Constituzionale e na literatura brasileira, 0 artigo pioneiro de MARIA CELINA BODIN DE MORAES, A caminho de um Direito Civil Constitucional e a monografia de Teresa Negreiros, Fundamentos para uma interpretação constitucional do princípio da boa-fé. Renovar, 1998.

35. "El daño fundado en la dimensión del hombre en su concreta realidad", in Daños a la persona. Revista de Derecho Privado y Comunitário. T. 1. Buenos Aires: Rubinzal-Culzoni, 1995, p. 11. 
necesaria aproximación a la calidad ontológica del bien a tutelar (que) nos permitirá precisar tanto los criterios como la técnica jurídica susceptibles de utilizar para lograr este primordial objetivo". ${ }^{36} \mathrm{Ou}$ como entre nós afirmou recentemente JOSAPHAT MARINHO ao aludir à disciplina dos direitos da personalidade, "o homem, por suas qualidades essenciais, e não propriamente o dado econômico, torna-se o centro da ordem jurídica". ${ }^{37}$

A compreensão da dimensão e da operatividade deste princípio permite o enfrentamento jurídico de alguns aspectos que têm sido apontados pela Bioética como suas questões centrais. Por exemplo, em matéria de reprodução humana assistida, principalmente aquelas relativas à fecundação in vitro, é a tutela jurídica da pessoa que tem provocado verdadeira revolução no domínio da responsabilidade extrapatrimonial, por forma a permitir a solução de questões ligadas a falhas na segurança do material genético doado, seja devido à transmissão de defeitos genéticos, de doenças infecciosas, seja à guarda do material doado (possibilidade de furto, de destruição não intencional, de manipulação cri-

minosa, de troca, por negligência, do material de um doador por outro, etc.).

Também as tormentosas questões relativas à relação entre médico e paciente, seja na ponderação entre o princípio (bioético e jurídico) da autonomia, de um lado, e o dever médico de beneficência, de outro, podem ser melhor equacionadas pela concreção do princípio da dignidade da pessoa. ${ }^{38}$ Este desdobra-se, além do mais, em outros princípios constitucionais, como o da tutela à vida privada e à intimidade, ${ }^{39}$ o que tem ensejado aos Tribunais reequacionar casos de responsabilidade médica, por exemplo, pela indevida divulgação de dados relativos ao paciente, ou pela ausência de cuidados relativos ao bom resguardo do sigilo médico. ${ }^{40}$

Será o princípio infringido - devendo a sua violação, ou a ameaça de violação receber resguardo jurídico, seja através de tutelas preventivas, seja mediante conseqüências indenizatórias, seja por cominações de nulidade - nos casos de mercantilização de sêmens e embriōes e do próprio ser humano ("mães-de-aluguel"), ou, ainda em matéria de RHA, diante da possibilidade de eugenia, que também in-

36. "Protección a la persona humana". In Revista Ajuris n 56. Porto Alegre, 1992, pp. 87 e 88.

37. "Os Direitos de Personalidade no Projeto do Novo Código Civil Brasileiro". In Boletim da Faculdade de Direito da Universidade de Coimbra, col. Stvdia Ivridica, 40, in Portugal-Brasil ano 2000, Coimbra, 2000.

38. Que se apresenta como a tradução jurídica de princípios bioéticos, como demonstram ESTHER LOPES PEIXOTO (A tutela da engenharia genética: reflexões sobre a sua concretização no âmbito do Direito Privado) e PAULO GILBERTO COGO LEIVAS ( $A$ genética no limiar da eugenia e a construçãa do princípio da dignidade da pessoa humana), ambos integrantes de "A reconstrução do Direito Privado - reflexos dos princípios constitucionais e dos direitos fundamentais no Direito Privado", org. Judith MartinsCosta, citado.

39. $C F$, art. $5^{8}$, inc. $X$.

40. Veja-se 0 ensaio de LUCIANA MABILIAMARTINS, "O Direito Civil à Privacidade e à Intimidade", também integrante de A recons trução do Direito Privado - reflexos dos princípios constitucionais e dos direitos fundamentais no Direito Privado, org. Judith Martins-Costa, citado.

Revista da Faculdade de Direito da UFRGS, v. 18, 2000 fringe o princípio constitucional da igualdade, ${ }^{41}$ o qual proíbe qualquer discriminação, por raça, sexo ou gênero.

A concreção do princípio da dignidade da pessoa pode solucionar, ainda, algumas questões ligadas ao direito de família, resultantes, por exemplo, da exigência de consentimento do marido ou companheiro e à irrevocabilidade deste consentimento. Assim como ninguém pode ser compelido a ser doador de sêmen, ou a aceitar a paternidade de criança que é biologicamente descendente de outra pessoa, pois a autonomia é conseqüência do reconhecimento da dignidade, assim também o é a auto-responsabilidade. Por isto, nos casos em que houve inseminação heteróloga, com o consentimento do companheiro, gerado o novo ser, este tem a sua dignidade reconhecida. Nesta perspectiva, o princípio da dignidade da pessoa conduz a uma interpretação conforme a Constituição das demais regras do sistema acaso não perfeitamente compatíveis e dos demais princípios, inclusive os bioéticos, tais quais os constantes do Código de Ética Médica, ${ }^{42}$ de modo a poder-se concluir pela preclusão do direito do homem que consentiu com a inseminação artificial heteróloga em sua mulher a impugnar posteriormente a paternidade, que é presumida.

41. CF, art. $5^{2}$, caput.

42. Que integram 0 ordenamento jurídico, na medida em que atuam como tópicos hermenêuticos no momento da aplicação do Direito.

43. VIDAL, Marciano. "Clonagem: Realidade Técnica e Avaliaçăo Ética", in Ética e Engenharia Genética, Concilium/275 - 1998-2. Rio de Janeiro: Vozes, 1998, pp. 125-137.

44. VIDAL, op. cit., p. 129.

45. E, por isto mesmo expressando-se seja por meio da literatura (o desejo fáustico de perpetuar-se idêntica e indefinidamente, ou 0 dublê de Dorian Gray para Oscar Wilde), do cinema de ficção científica ("Meninos do Brasil"), da revanche feminista da procriação sem a presença masculina, dos mitos acerca da procriaçăo virginal ou assexuada, ou dos "duplos" Castor e Pólux de que fala a mitologia grega (ver VIDAL, op. cit., pp. 130-131).
O princípio tem fundamental importância também no que concerne ao tema da clonagem em seres humanos. diferenciada, um jornal inglês expressou, numa manchete um tanto alarmista, a perplexidade que ainda nos domina: "Hoje a ovelha, amaṇhã o pastor". ${ }^{43}$ A clonagem, em si mesma considerada, pode trazer benefícios, um dos quais é o progresso da ciência, sabendo-se que a pesquisa básica é um dos horizontes axiológicos da humanidade e o conhecimento científico um dos grandes interesses humanos. ${ }^{44}$ Contudo, sem esquecer os benefícios que a clonagem efetivamente traz, resta a questão ética que reflete-se necessariamente no Direito.

A questão ética em torno dos clones humanos, um dos temas recorrentes do imaginário humano, como lembra MARCIANO VIDAL ${ }^{45}$ recoloca no centro do debate bioético e biojurídico, e em plena era da chamada Pós-Modernidade, um dos eixos centrais da Modernidade, qual seja, a idéia de um Direito com valor universal, centrado na ética kantiana acerca da dignidade da pessoa humana: em todas as discussões que têm sido levadas a efeito nos meios' científicos e nos comitês de
Em 1997, quando criou-se a famosa Dolly a partir da clonagem de uma célula

Revista da Faculdade de Direito da UFRGS, v. 18, 2000 

como fim. bioética, o questionamento ético básico é o de utilizar um ser humano como meio e não

É do jusfilósofo VICENTE BARRETTO a sagaz percepção da idéia kantiana de um "direito cosmopolita" como fundamento de uma disciplina ora nascente, o Biodireito. Numa época em que Direito e Filosofia não estavam perfeitamente distinguidos, Kant investigou a possibilidade de uma ordem jurídica fundada em valores universais e, à diferença dos filósofos que $\mathrm{o}$ antecederam, abandona a tradição jusnaturalista fundada na existência de princípios inatos ou naturais e lança a idéia de um "direito cosmopolita". ${ }^{46}$

Em rapidíssima síntese, consiste direito cosmopolita no tipo de norma que ultrapassa as comunidades nacionais e identifica-se como sendo a norma de uma comunidade planetária. Assentou Kant no "Projeto para uma Paz Perpétua", de 1790, que "em todos os lugares da terra rege-se de uma forma idêntica à violação do direito cosmopolita", sendo este direito "um complemento necessário do código não escrito, tanto no direito civil, como no direito das gentes, em vista do direito público dos homens em geral".47 Como explica BARRETTO, a idéia kantiana de direito cosmopolita refere-se, principalmente, ao entendimento de que a evolução histórica, e com ela as luzes da razão, iriam encontrar normas com fundamentação ética, que poderiam ser consideradas como uma forma

de direito, que se imporiam com a força de sua própria racionalidade.

Por isto propõe, com integral pertinência, a utilização desta categoria para determinar até que ponto os valores éticos podem constituir-se em categorias racionalizadoras e légitimadoras de uma nova ordem jurídica, a que defronta-se e enfrenta os problemas trazidos pelo progresso científico, na medida em que "essa categoria do direito cosmopolita permite que se tenha uma leitura propriamente moral dos direitos humanos, podendo-se mesmo entender essa categoria de direitos como uma manifestação dos valores éticos no sistema jurídico". ${ }^{48}$

Ora, se a maioria das Constituições dos países ocidentais reconhece, de forma implícita ou explícita o princípio da dignidade da pessoa humana como o valor-fonte do ordenamento, é preciso reconhecer que a proposição kantiana retomada por BARRETTO concilia-se à perfeição não só com o comum topos constitucional mas, igualmente, com a série crescente de documentos e regulações, éticos e jurídicos, que pretendem ter validade universal, e do qual é o maior exemplo a recente Declaração Universal do Genoma Humano e dos Direitos Humanos, adotada pelo consenso de mais de 80 Estados representados na reunião do Comitê de Especialistas Governamentais do Comitê de Bioética da UNESCO, e apresentada para adoção na 29a Sessão da Conferência Geral da

46. BARRETO, Vicente de Paulo. "Bioética, biodireito e direitos humanos", in Teoria dos Direitos Fundamentais (org.) de Ricardo

47. Idem, p. 381. A citaçăo refere-se ao texto de Kant, transcrito por BARRETTO.

48. Idem, p. 379. Lobo Torres. Renovar, 1999, p. 378.
UNESCO realizada entre 21 de outubro e

Também refletindo o "direito cosmopolita" e igualmente assentados sobre o mesmo fundamento estão vários textos normativos internacionais, ${ }^{50}$ entre os quais destaca-se a Convenção sobre Direitos Humanos e Biomedicina adotada em 1996 pelo Conselho de Ministros do Conselho da Europa ("Convenção de Oviedo"), cuja configuração é de uma "convenção-quadro" "destinada a preencher o vazio jurídico no qual a biomedicina e suas aplicações (a genética) tem podido evoluir até o presente momento", como acentua PATRICK FRAISSEIX. ${ }^{51}$ Entre os consideranda constantes no seu Preâmbulo está a advertência de que o uso desviado da Biologia e da Medicina pode conduzir à prática de atos que ponham em risco a dignidade humana. resses e o bem-estar do ser humano devem prevalecer sobre o interesse isolado da sociedade ou ciência - escalonando, assim, 12 de novembro de 1997.49

O seu art. $2^{\circ}$ determina que os inte- os valores da dignidade e do progresso científico, com preeminência do primeiro. Em ambas, seja na Convenção européia, seja na da UNESCO, encontra-se explícita a idéia de dignidade em sua dupla acepção, a dig. nidade do homem e a da humanidade, à qual se agrega a idéia da salvaguarda da identidade humana como identidade da espécie humana.

Os textos normativos da mais variada escala o afirmando, não só aos juízes, na tarefa de aplicar o Direito, e a comunidade científica, como destinatária das regras e princípios do ordenamento é que dirige-se o princípio da dignidade da pessoa humana. Este também está endereçado ao legislador infraconstitucional, que tem ao seu blemáticos. A lei tem, muitas vezes, um valor simbólico, impondo com mais facilidade os limites que poderiam ser, em tese, deduzidos dos princípios constitucionais e daqueles afirmados nas convenções internacionais. ${ }^{52}$ encargo o regramento de alguns casos pro-

49. A Declaração Universal do Genoma Humano e dos Direitos Humanos de 1997, após afirmar que "o genoma humano subjaz à unidade fundamental de todos os membros da familila humana e também ao reconhecimento de sua dignidade e diversidade
inerentes", constituindo, num sentido simbólico, "a herança da humanidade" (art. $1^{\circ}$ ) veda a possibilidade de o genoma humano em seu estado natural "dar lugar a ganhos financeiros" (art. $4^{\circ}$ ) e próibe, taxativamente, "práticas contrárias à dignidade humana, tais como a clonagem reprodutiva de seres humanos" (art. 11). Toda a Declaraçãoo é fundada no princípio da dignidade da pessoa humana, "direito de todos" (art. $2^{\circ}$, primeira parte) a qual resta especificada, neste campo, pela vedação de reduzir-se os individuos "a suas características genéticas", impondo o respeito a "sua singularidade e diversidade" (idem, segunda parte).

50. Assim as normas que, ao longo do tempo, em especial a partir dos anos 80 , vêm sendo produzidas pela Assembléia Parlamentar do Conselho da Europa, em especial as suas recomendaçőes e resoluçōes como, exemplificativamente, as relativas aos direitos dos pacientes ( $n^{n}$ 616/76); à utilização de embriōes e fetos humanos para fins diagnósticos, terapêuticos, científicos, industriais e comerciais ( $n^{0} 1.046 / 86$ e 1.100/89), à AIDS e aos direitos humanos ( $\left.n^{0} 1.116 / 89\right)$, à harmonização das regras em matéria de autópsia ( $\left.n^{0} 1.159 / 91\right)$, a relativa à elaboração de uma Convenção de Bioética ( $\left.n^{2} 1.160 / 91\right)$, que veio a resultar na Convenção de Oviedo.

51. "La protection de la dignité de la personne et de l'espèce humaines dans le domaine de la biomédecine: l'exemple de la Convention $d^{\prime} O$ viedo". Revue Internationale de Droit Comparé, 2, avril-juin 2000, p. 372.

52. Há questōes que, por sua minudência, carecem de uma punctual regulamentação legislativa. Entre nós na questão da clonagem vigora a Lei $n^{0} 8.974 / 95$, que estabeleceu as normas para uso das técnicas de engenharia genética. $O$ item IV do art. $8^{2}$ veda a "produção, armazenamento ou manipulação de embriōes humanos destinados a servir como material biológico disponivel". Da mesma forma, a Comissão Técnica Nacional de Biossegurança (CTNBio), vinculada ao Ministério da Ciência e Tecnologia, talvez 
O fato de o princípio dirigir-se ao legislador significa, fundamentalmente, que este está adstrito à sua observância por ocasião da elaboração legislativa. Em outras palavras, o legislador não é livre para elaborar o conteúdo da lei, pois, na forma do sistema constitucional vigente, deve observar os valores postos na Constituição, auxiliando a sua concreção, sob pena de inconstitucionalidade da lei.

Várias questões estão a merecer regulamentação punctual, como a questão do incesto: a proibição jurídica do incesto pode ser infringida na técnica da RHA heteróloga em razão da exigência de anonimato dos doadores. Dois valores, então, entrarão em choque, de um lado, a proteção da privacidade do doador, de outro, o direito da criança assim gerada de conhecer a sua ascendência biológica.

Também está a merecer urgente regulamentação a candente questão da apropriação e mercantilização do material genético, que poderia ser objeto de registro e patenteamento, recaindo, assim, sob as regras da propriedade intelectual. $O$ anúncio da descoberta da cartografia genética colocou este tema na ordem do dia. O governo francês assegurou, pelo seu Ministro da Pesquisa da França, ROGER-GÉRARD SCHWARTZENBERG, que os dados do projeto Genoma "foram colocados à dispo- sição do domínio público desde sua obtenção, sem restrição de utilização", entendendo que as seqüências brutas do genoma humano não podem ser patenteadas porque "o saber genético não pode ser confiscado." Contudo, esta não é uma posição consensual. No mesmo dia, o Diretor Adjunto do Centro Nacional de Seqüenciamento, o Genoscope, órgão que representa o país no Projeto Genoma $\mathrm{Hu}$ mano, FRANCIS QUETIER, afirmou à imprensa não haver "harmonização entre países parceiros no projeto, principalmente entre EUA e Europa", no que se refere ao patenteamento de genes. ${ }^{53}$

No Brasil, vem de ser editada a Medida Provisória no $2.052^{54}$ pela qual as instituições nacionais da área biológica podem se associar a instituições estrangeiras para. pesquisar amostras de componentes do patrimônio genético do país, podendo inclusive o material ser remetido para o exterior. ${ }^{55}$ Empresas privadas, como a norte-americana Celera, realizam o seqüenciamento do código genético e, com certeza, utilizarão seus dados segundo a lóapropriação e de lucro, produzindo conhecimento para ser vendido.

Para além dos danos que pode trazer à humanidade (por exemplo, ao restringir o acesso aos dados por barreiras econômicas) gica do mercado, como objeto suscetível de

extrapolando a sua competência legal, baixou uma Instrução Normativa $n^{9} 08 / 97$, de 09 de julho de 1997, proibindo a manipulação genética de células germinativas ou totipotentes humanas, assim como os experimentos de clonagem em seres humanos. Vale ressaltar que atualmente existem quatro projetos de lei tramitando no Congresso Nacional sobre a questão da clonagem de seres humanos.

53. Folha de São Paulo, Caderno Ciência de 27.06.2000

54. Publicada no DOU de 30 de junho de 2000.

55. Desde que assinado Termo de Transferência ou Contrato. a mercantilização do material genético implica também em atentado à vida privada: empresas de seguros poderão, com bases nesses dados, recusar seguro, ou aumentar o valor do prêmio, em face da potencialidade do organismo para certas doenças e empregadores poderão recusar trabalho. ${ }^{56}$

Todas estas são angustiantes questões que animam e justificam a reflexão bioética, encontrando, porém, possível via de enfrentamento jurídico com base no princípio da dignidade e nas regras legais que para a sua concreção concorram.

Resta, contudo, a questão fundamental do Biodireito, para a qual o mencionado princípio não aponta de imediato uma solução: esta reside na própria idéia de "pessoa" que está na sua base. ${ }^{57}$

Se já há um relativo consenso na comunidade internacional acerca da valência do princípio da dignidade da pessoa humana como cânone hermenêutico e integrativo para o juiz, como fonte de criação de deveres ao legislador e como imposição de limites aos cientistas, havendo concordância em fixar os limites da ação manipulativa não terapêutica lícita e ilícita no reconhecimento da pessoa, não se sabe, porém, quem deve ser considerado pessoa.

O conhecimento científico fez com que houvesse uma verdadeira "décalage" entre o conceito jurídico de "pessoa" e o conceito científico de "ser humano vivo". É bem verdade que, na história, nem sempre houve a coincidência (basta pensar no estatuto do escravo e na personificação das coisas e animais, própria ao pensamento arcaico), havendo, contudo, indicações da coincidência já no Direito Romano e no Direito Medieval, ${ }^{58}$ muito embora certos textos romanos vissem no embrião mera parte das vísceras maternas, portio mulieros vel viscerum. ${ }^{59}$

A Modernidade, ao construir os conceitos gerais-abstratos, assentou duas máximas que até hoje fazem fortuna, qual seja, "todo o homem é pessoa" e "só o homem é pessoa", qualificando, porém, como "homem" (ou como "pessoa") o ser humano nascido com vida. A qualificação de pessoa restou assim condicionada a um determinado momento (o do nascimento), então tido como o do início da vida. Para o Direito vigente a "pessoa" à qual é reconhecida o atributo da "personalidade", sendo portanto "sujeito" é o ser que nasce com vida, ${ }^{60}$ findando-se a personalidade com a morte.

Esta é a qualificação que agora vem posta em xeque, pois enquanto o Direito

6. "Nos EUA, a lei regula estes casos, proibindo a discriminação com base em handicap" (Reabilitation Act de 1973 e 0 Americans with disabilities act, de 1990).

57. Para uma análise da "aventura semântica" que recobre o termo "pessoa" em perspectiva histórico-filosófica, e da sua atual recuperaçăo como categoria prática, veja-se L. PALAZZANI, op. cit.

58. Demonstrando a existência de regras que asseguravam a paridade, no plano normativo, entre os conceitos de nascituro $\theta$ nascido, PIERANGELO CATALANO, "Os nascituros entre o Direito Romano e o Direito Latino-Americano", in Revista de Direito Civil, vol. 45, 1988, p.55.

59. Esta é a indicação que é difundida nos manuais. Assim, CAIO MÁRIO DA SILVA PEREIRA, Instituiçōes de Direito Civil, 14. ed., vol. I, Forense, 1993, p. 158, sem indicação da fonte romana.

60. Código Civil, art. $4^{2}$, assegurando-se ao nascituro não o atributo da personalidade, mas certos direitos se chegar a nascer.

Revista da Faculdade de Direito da UFRGS, v. 18, 2000 
situa o início da vida no nascimento, a lização (fecundação ou concepção), inclusive a Psicologia percebendo já no embrião as características de individualidade e singularidade próprias de cada ser humano. ${ }^{61}$

Por isto é que, como assinala LAURA PALAZZANI, "a originária e intuitiva co posta em dúvida no debate bioético e biojurídico, com a conseqüente exclusão de alguns seres humanos do reconhecimento do estatuto de pessoa". ${ }^{62}$ A décalage entre Direito e a Biociência, fundando-se na separação entre vida biológica do ser humano e vida da pessoa, decorre da "teorização da post-cipação do início da pessoa ao início da vida do ser humano e da ante-cipação do fim da pessoa ao fim da vida do ser humano". 63

Esta é, por conseqüência, a questão fundamental, o horizonte problemático da Bioética e do Biodireito.

Contudo, se como procurei demonstrar, não mais sobrevive a ficção de que o Direito é uma "ciência pura", separada da Ética - se pelo contrário, os grandes temas jurídicos são também os grandes temas éticos - será tarefa da reflexão bioética fornecer ao Direito os parâmetros que permitirão Biociência o situa anteriormente, na fertiincidência entre 'pessoa' e 'ser humano' está

a reconstrução da idéia de pessoa fundada na coincidência entre pessoa e ser humano. Poder-se-á pensar, assim, na extensão da idéia de "dignidade da pessoa" de um quadro de singularidade, que a caracterizou no século XX, para a apreensão daquilo que, no conceito, relaciona-se com o gênero humano, preenchendo-se o conteúdo do princípio com a noção de uma "dignidade da humanidade" que, entendida concreta, e, portanto, historicamente, atue como guia, critério e limite aos dilemas trazidos pela Revolução Biotecnológica.

\section{Bibliografia}

ALEXY, Robert. Teoria de los Derechos Fundamentales (trad. de Ernesto Garzón Valdés). Madri, Centro de Estudios Constitucionales, 1993.

BARRETTO, Vicente de Paulo Barretto. "Bioética, biodireito e direitos humanos". In Teoria dos Direitos Fundamentais (org de Ricardo Lobo Torres). Renovar, 1999, p. 378.

CANARIS, Claus-Wilhem. Pensamento Sistemático e Conceito de Sistema na Ciência do Direito (trad. de Antonio Menezes Cordeiro). Lisboa: Fundação Gulbenkian, 1989.

CATALANO, Pierangelo. Os nascituros entre o Direito Romano e o Direito Latino-Americano. Revista Direito Civil, vol. 45, 1988, p. 55

61. É de ser registrada a percepção de PONTES DE MIRANDA, nos meados do século transcurso, ao afastar as teorias ficcionistas, que construiram a proteção do nascituro com a ficção de já ter nascido, ou as que pretendiam qualificar o nascituro como se personalidade tivesse em decorrência do ińcio da vida, identificando "homo e persona, o que vai entrar na vida social e o que já entrou" (Tratado de Direito Privado, T. I, §51). "Tal identificaçäo", afirma, "foge à verdadeira natureza do direito: protege-se o feto como ser vivo, como se protege o ser humano já nascido, contra atos ilícitos absolutos e resguardam-se os seus interesses, para o caso de nascer com vida: biologicamente, o conceptus sed non natus já é homem: juridicamente, esse ser humano ainda não estreou na vida social, que é onde se enlaçam as relaçōes jurídicas" (idem, ibidem)

62. Op. cit., p. 3, traduzi.

63. Idem, p. 34, tradução minha.

Revista da Faculdade de Direito da UFRGS, v. 18, 2000
CUNHA, Alexandre dos Santos. "Dignidade da Pessoa Humana: conceito fundamental do Direito Civil". In A reconstrução do Direito Privado - reflexos dos princípios constitucionais e dos direitos fundamentais no Direito Privado, org. Judith Martins-Costa, no prelo.

D'ORMESSON, Jean. Au plaisir de Dieu. Paris: Gallimard, 1974.

EDELMAN, Bernard Edelman. "Sujet de droit et technoscience". In La personne en danger. Paris: PUF, 1999.

. "La dignité de la personne humaine,

un concept nouveau". In La personne en danger. Paris: PUF, 1999.

FRAISSEIX, Patrick. "La protection de la dignité de la personne et de l'espèce humaines dans le domaine de la biomédecine: l'exemple de la Convention d Oviedo". In Revue Internationale de Droit Comparé, $n^{\circ} 2$, avril-juin 2000.

GREIMAS, A J. Semiótica e Ciências Sociais (trad. de Alvaro Lorencini e Sandra Nitrini). São Paulo: Cultrix, 1981.

HATTENHAUER, Hans. Conceptos fundamentales del Derecho Civil (trad. Pablo Salvador Coderch). Barcelona: Ariel, 1987.

HERMITTE, Marie-Angèle. "Le corps hors du commerce, hors du marché". In Archives de Philosophie du Droit, n 33, 1988.

LAFER, Celso. A Reconstrução dos Direitos Humanos - um diálogo com o pensamento de Hannah Arendt. São Paulo: Companhia das Letras, 1991.

LARENZ, Karl. Metodologia da Ciência do Direito (trad. de José Lamego). Lisboa: Fundação Calouste Gulbenkian, 1997.

LEIVAS, Paulo Gilberto Cogo. "A genética no limiar da eugenia e a construção do princípio da dignidade da pessoa humana". In A reconstrução do Direito Privado - reflexos dos princípios constitucionais e dos direitos funda- mentais no Direito Privado, org. Judith Martins-Costa, no prelo.

MARINHO, JOSAPHAT. "Os Direitos de Personalidade no Projeto do Novo Código Civil Brasileiro". In Boletim da Faculdade de Direito da Universidade de Coimbra, col. Stvdia Ivridica, 40. Portugal-Brasil ano 2000, Coimbra, 2000.

MARTINS, Luciana Mabilia. "O Direito à Privacidade e à Intimidade”. In A reconstrução do Direito Privado - reflexos dos princípios constitucionais e dos direitos fundamentais no Direito Privado, org. Judith Martins-Costa, no prelo.

MARTINS-COSTA, Judith. A Boa-Fé no Direito Privado. São Paulo: Revista dos Tribunais, 1999.

MESSINETTI, Davide. "Personalitá" (Diritti della), verbete. In Enciclopedia Giuridica. Giuffrè: Milão, 1984, p. 356.

MOISSET ITURRASPE, J. "El daño fundado en la dimensión del hombre en su concreta realidad". In Daños a la persona. Revista de Derecho Privado y Comunitário. T. 1, Buenos Aires: Rubinzal-Culzoni, 1995.

MORAES, Maria Celina Bodin de. "A caminho de um Direito Civil Constitucional". In Revista Direito, Estado e Sociedade, PUC, $\mathrm{n}^{\circ} 1$. Rio de Janeiro, 1991.

NEGREIROS, Teresa. Fundamentos para uma interpretação constitucional do princípio da boafé. Rio de Janeiro: Renovar, 1998.

PALAZANNI, Laura. Il concetto di persona tra bioetica e diritto. Turim: Giappichelli, 1996.

PEIXOTO, Esther Lopes. "A tutela da engenharia genética: reflexões sobre a sua concretização no âmbito do Direito Privado". In A reconstrução do Direito Privado reflexos dos princípios constitucionais e dos direitos fundamentais no Direito Privado, org. Judith Martins-Costa, no prelo. 
PEREIRA, Caio Mario da Silva. Instituições de Direito Civil. Vol. I, 14. ed., Forense, 1993.

PERLINGIERE, Pietro Perlingiere. Il Diritto Civile nella Legalità Constituzionale. Nápoles: Edizione Scientifiche Italiane, 1991.

PONTES DE MIRANDA, J. Tratado de Direito Privado. T. I, Rio de Janeiro: Borsoi, 1954.

RAPOSO, Mário. "Procriação Assistida - As. pectos Éticos e Jurídicos". In Direito da Saúde e Bioética. Lisboa: Lex, 1991.

REALE, Miguel. Teoria Tridimensional do Direito. São Paulo: Saraiva, 1994.

. Verdade e Conjetura. São Paulo: Nova Fronteira, 1983.

. Fundamentos do Direito. São Paulo: Revista dos Tribunais, 1998.

. Fontes e Modelos do Direito - para um novo paradigma hermenêutico. São Paulo: Saraiva, 1994
SESSARIEGO, Carlos Fernandez. "Protección a la persona humana". In Revista Ajuris $n^{0}$ 56. Porto Alegre, 1992.

TABORDA, Maren. A Publicização da noção de pessoa jurídica como fator de construção da dogmática do "Estado de Direito". Porto Ale. gre, 2000, datilografado, inédito.

VIDAL, Marciano. "Clonagem: Realidade Técnica e Avaliação Ética”. In Ética e Engenharia Genética, Concilium/275 - 1998-2. Rio de Janeiro: Vozes, 1998.

VIOLA, Francesco, e ZACCARIA, G. Diritto e Interpretazione - Lineamenti di teoria ermeneutica del diritto. Roma: Laterza, 1999.

ZACCARIA, Giuseppe. "Sul Concetto di Positività del Diritto". In Diritto Positivo e Positività del Diritto (org. G. Zaccaria). Milão: Giappichelli, 1989.

\section{Algumas contribuições da ciência histórica à tarefa do historiador do Direito}

\author{
Launa Beck Pavela
}

Mestranda em Direito pela UFRGS.

El historiador no ofrece modelos, sino que señala el sentido de la línea. Digamos que disuelve el absolutismo del presente relativizándolo gracias a su inserción em la línea, pero dotándole así también de uma conciencia más aguda de la propia dirección, de una dirección que no se encuentra certeramente trazada por um incesante movimiento evolutivo bajo el signo de un constante progreso, sino que está circunstanciadamente trenzada com el recurso de la única riqueza disponible para la experiencia humana, la vida enteramente vivida, en exposición completa com todo su patrimonia de valores y desvalores" 1 (PAOLO GROSSI, Professor de História do Direito da Universidade de Florença, Itália)

\section{SUMÁRIO:}

Introdução.

I- Notas sobre a ciência histórica.

II - Algumas contribuições da ciência histórica à tarefa do historiador do Direito.

Conclusão.

Bibliografia.

\section{Introdução}

herança positivista legou à teoria do A direito a identificação entre este e a lei, afastando-o da consideração de quaisquer elementos que não fossem estritamente jurídicos. Paralelamente, a vertente filosófica do jusnaturalismo racionalista contribuiu para a preponderância da concepção de um direito a-histórico, eterno, imutável. ${ }^{2}$

Há algumas décadas, contudo, têm surgido escritos sobre História do Direito, revelando a preocupação de traçar a evolu. ção do fenômeno jurídico e da forma de pensar o direito, suas continuidades e

1. PAOLO GROSSI, "El punto y la línea (historia del derechoy derecho positivo en la formación del jurista del nostro tiempo)", discurso proferido por ocasião do recebimento do título de doutor honoris causa na Universidade de Sevilha, 1998, p. 29.

2. A elaboração dos códigos civis, nos séculos XVIII e XIX, corresponderia ao ápice de uma evolução que se vinha decorrespondera ao ápice do un lineando desde os romanos. Trata-se do equivalente juridico da noçáa de progresso historico (Conforme LE GOFF, Historia e Memóra, p. 14). PAOLO GROSSl aponta os fabres que explicam o tenomeno que ousamos chamar de
"deshistoricização" do direito (ob. cit., p.20). 